\title{
Discharge and atmospheric dispersion modelling in case of hazardous material releases
}

\author{
Vlad Mihai Pasculescu ${ }^{1 *}$, Emilian Ghicioi ${ }^{1}$, Ligia Ioana Tuhut ${ }^{1}$, Adrian Bogdan Simon- \\ Marinica ${ }^{1}$, and Dragos Pasculescu ${ }^{1}$ \\ ${ }^{1}$ National Institute for Research and Development in Mine Safety and Protection to Explosion - \\ INSEMEX, 32-34 G-ral Vasile Milea Street, 332047, Petrosani, Hunedoara County, Romania
}

\begin{abstract}
One of the most important tools for improving the OHS level in process industries is represented by risk analysis and assessment. Within industrial units in operation or in the ones which find themselves in the design phase, risk assessment is carried out for determining the hazards which may occur and which may lead to unwanted events, such as hazardous toxic releases, fires and explosions. Accidental releases of toxic/flammable/explosive substances may have serious consequences on workers or on the neighbouring population, therefore the need to establish safety areas based on best practices in the field and on scientific grounds is fully justified. Pressure tanks containing hazardous materials represent one of the most relevant industrial facilities within process plants, being most of the time exposed to hazardous toxic releases, fire and explosion risks. The current study aims to evaluate the consequences and discuss the safety distances required in case of an accidental release of a hazardous material from a tank located within a process plant, using process analysis software tools. Accident scenarios are modelled for comparison purposes with consequence modelling software widely used in safety engineering.
\end{abstract}

\section{Introduction}

Accidental releases of toxic/flammable/explosive substances may have serious consequences on workers or on the neighbouring population, therefore the need to develop safety reports based on best practices in the field and on scientific grounds is fully justified.

Pressure tanks containing hazardous materials represent one of the most relevant industrial facilities within process plants, being most of the time exposed to hazardous toxic releases, fire and explosion risks. Nowadays, safety engineers and specialists are making more and more use of quantitative risk assessment software which can simulate various accident scenarios occurring in the industry, such as toxic releases, fires and explosions [1].

In this study there were compared the results obtained with two such programs: the first one is ALOHA, which is the abbreviation of Areal Locations of Hazardous Atmospheres and the second one is Phast, the name of the software standing for Process Hazard Analysis

* Corresponding author: vlad.pasculescu@insemex.ro 
Software Tool. There have been modelled accident scenarios involving the accidental release of two hazardous substances: ammonia and hydrogen chloride.

\section{Selected chemical substances}

In most developed countries, the industrial facilities are clearly separated from civil areas, being regulated by various norms, plans, laws and so on. For example, in the European Union, the main law which deals with the control of major accidents which can occur due to dangerous substances is the Seveso Directive. For preventing such accidents, there has to be carried out a proper safety management in order to ensure optimal safety distances from industrial units to civil areas. The safety distances are established within the risk assessment process [1].

The current study uses two substances for performing the computer simulations of their accidental release. These are considered to be highly acute toxic substances, requiring special management. Industrial units which circulate dangerous substances have to prepare for possible accidents [2-4]. The two chemical substances used for accident modelling in this study are hydrogen chloride (CAS number 7647-01-0) and ammonia (CAS number 7664-41-7).

Risk assessments carried out in industrial units are performed using several wellestablished methods, but are nowadays making more and more use of dedicated software which are able to model a variety of accident scenarios and which are base on validated mathematical models. Internal Emergency Plans are developed for reducing the risk for the workers, quality of the environmental factors and for the integrity of goods in case there may occur accidents involving hazardous substances which are presented within the unit. There has to be taken into account that compared to fires and explosions which may be extended to the borders of the industrial unit, the leakage of a toxic substance may be spread due to weather conditions and can affect residential areas nearby.

\section{Modelling program selection}

The ALOHA software is a free program developed and used by the USEPA (United States Environmental Protection Agency). With the help of this program, the air concentrations of some gas discharges can be predicted. The mathematical model underlying the program works well with certain limitations (low wind speeds - which do not produce interaction phenomena, very stable weather conditions, slow changes in wind direction, slow variations in concentrations) [1].

The objective of the program is to support decision-makers responsible for chemical releases to the atmosphere in the resolution of emergencies and training in order to establish protection and intervention measures in such situations.

Phast Software is a commercial program designed for the analysis of technological hazards and the management of consequences in the process industries. Software is used to analyze situations that may pose a potential hazard to people, property, or the environment and to quantify them according to their severity [5]. The consequences can then be managed or reduced by designing the industrial process or by installation, modifying operational procedures or implementing other measures to eliminate them [6].

Phast provides a clear illustration of the consequences that may result from hazards in process industries (oil and gas, petrochemicals, chemicals, etc.). It is capable of modelling discharges, dispersion, radiation and explosions [7-11].

This two software contain several important critical input items to analyse the outcome modelling of accident scenarios. Weather conditions represent important input data when 
setting up the simulations. Meteorological stability, seasonal temperatures, humidity, wind speed and direction play a very important role in modelling such accidents $[1,2,9,10]$. ALOHA use MARPLOT to plot the graphical outputs on the simulations on maps (Figure 1a). In Phast, a GIS image has to be imported at the beginning of each study for plotting the graphical outputs on the map (for example an image imported from Google earth, as presented in Figure 1b).

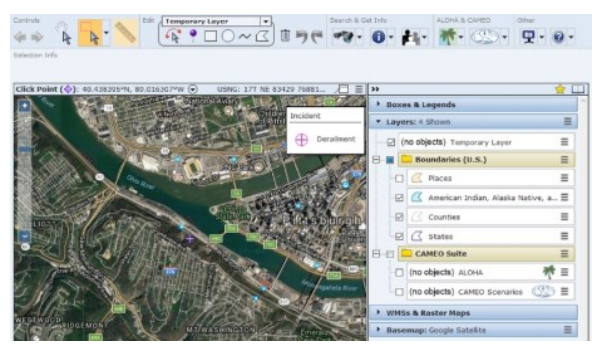

a) MARPLOT - ALOHA

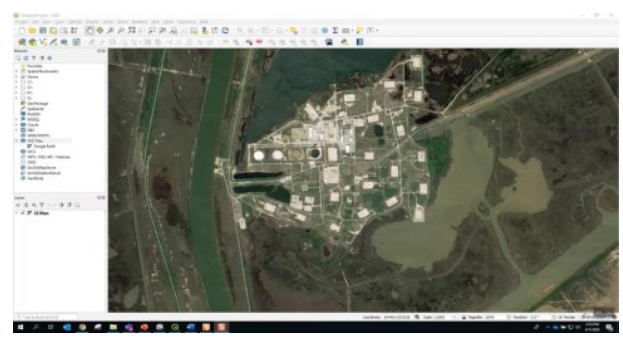

b) Google earth imported map in Phast

Fig. 1. Graphic results plotting

\subsection{Meteorological conditions}

The meteorological conditions can drastically influence simulations carried out with QRA software. In this regard, for comparison purposes the meteorological input data have been set the same in both software and are as follows:

- Wind speed: 2 meters/second

- Wind direction: North West to South East

- Cloud cover: partly cloudy

- Air temperature: $15 \mathrm{degC}$

- Pasquil stability class: C

- Relative humidity 50\%

\subsection{Exposure levels}

For calculating the exposure at endpoint concentrations, ALOHA uses AEGL Indices Acute Exposure Guideline Levels - (indicative level on acute exposure)

The AEGL estimates the concentrations at which most people - including sensitive people, such as the elderly, the sick or the very young - will start to have health effects if they are exposed to a dangerous chemical for a certain period of time.

- AEGL 3 - represents the value of the concentration in the air of a substance, expressed in $\mathrm{ppm}$ or $\mathrm{mg} / \mathrm{m} 3$, above which it is predictable that most people, including susceptible individuals, will suffer life-threatening effects or may cause death;

- AEGL 2 - represents the value of the concentration in the air of a substance, expressed in ppm or $\mathrm{mg} / \mathrm{m} 3$, above which most people, including susceptible individuals, are expected to suffer irreversible or serious long-term effects affecting their health or ability to self-evacuate;

- AEGL 1 - represents the value of the air concentration of a substance, expressed in ppm or $\mathrm{mg} / \mathrm{m} 3$, above which most people, including susceptible individuals, are expected to suffer appreciable discomfort, irritation or certain asymptomatic effects that do not affect the senses. However, the effects do not cause disability, are transient and reversible when exposure ceases;

Acute Exposure Guideline Levels in case of ammonia are:

- AEGL-1 (60 min): 30 ppm 
- AEGL-2 (60 min): $160 \mathrm{ppm}$

- AEGL-3 (60 min): 1100 ppm

Acute Exposure Guideline Levels in case of hydrogen chloride are:

- AEGL-1 (60 min): $1.8 \mathrm{ppm}$

- AEGL-2 (60 min): 22 ppm

- AEGL-3 (60 min): 100 ppm

Phast uses ERPG - Emergency Response Planning Guidelines (exposure levels for emergency response planning) which are exposure guidelines designed to anticipate health effects from exposure to certain chemical concentrations in the air. ERPG estimates the concentrations at which most people will start to have health effects if they are exposed to a hazardous chemical in the air for one hour.

- ERPG 1 - represents the maximum concentration in the air, due to which it is believed that almost all individuals can be exposed for an hour, experiencing only mild and transient side effects or noticing a well-defined odor;

- ERPG 2 - represents the maximum concentration in the air, due to which it is believed that almost all individuals can be exposed for one hour without experiencing or experiencing serious and irreversible effects or symptoms that may affect the possibility of applying protective measures;

- ERPG 3 - is the maximum concentration in the air, due to which it is believed that almost all individuals can be exposed for an hour without experiencing or experiencing life-threatening effects. Not coincidentally, they may suffer serious or irreversible effects and symptoms that may affect the ability to apply protective measures

Emergency Response Planning Guidelines levels in case of ammonia are:

- ERPG 125 ppm

- ERPG 2150 ppm

- ERPG 3750 ppm

Emergency Response Planning Guidelines levels in case of hydrogen chloride are:

- ERPG 13 ppm

- ERPG 220 ppm

- ERPG 3150 ppm

\subsection{Accident modelling - scenario 1}

The first accident scenario modelled with ALOHA and Phast involves the leak of ammonia from a horizontal cylindrical tank. The total volume of the tank is 10 cubic meters and it is $80 \%$ full. The chemical substance leaks through a circular opening in the tank which is 5 centimetres in diameter. The release location elevation is $0.5 \mathrm{~m}$. The mass inventory of the substance in both software has been set to 4945 kilograms which corresponds to $80 \%$ of the tank volume.

\subsection{Accident modelling - scenario 2}

The second accident scenario modelled with ALOHA and Phast involves the leak of hydrogen chloride from a horizontal cylindrical tank. The total volume of the tank is 10 cubic meters and it is $80 \%$ full. The chemical substance leaks through a circular opening in the tank which is 5 centimetres in diameter. The release location elevation is $0.5 \mathrm{~m}$. The chemical mass of hydrogen chloride in the tank is inventory of the substance in both software has been set to 6949 kilograms which corresponds to $80 \%$ of the tank volume. 


\subsection{Modelling results}

Simulation performed with ALOHA reveals the fact that for the discharge of ammonia from the tank through the circular $5 \mathrm{~cm}$ hole, the toxic gas cloud reaches the AEGL indices at the following distance from the source of release:

- AEGL $130 \mathrm{ppm}$ at a distance of $6.4 \mathrm{~km}$;

- AEGL $2160 \mathrm{ppm}$ at a distance of $3.2 \mathrm{~km}$;

- AEGL $31100 \mathrm{ppm}$ at a distance of $1.1 \mathrm{~km}$.

The toxic threat zone is represented graphically in Figure 3 and plotted using MARPLOT, as shown in Figure 4.

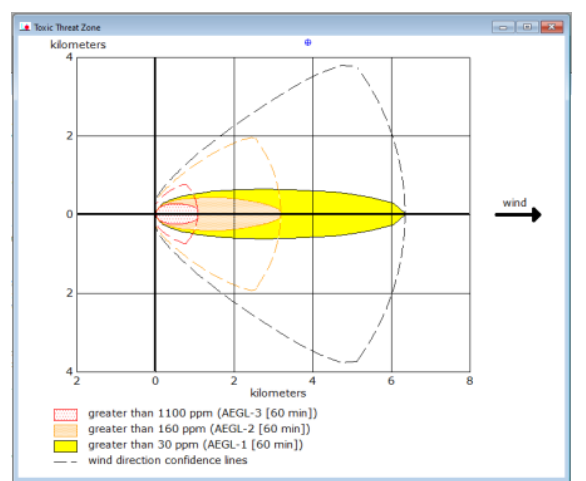

Fig. 3. Toxic threat zone - ammonia release

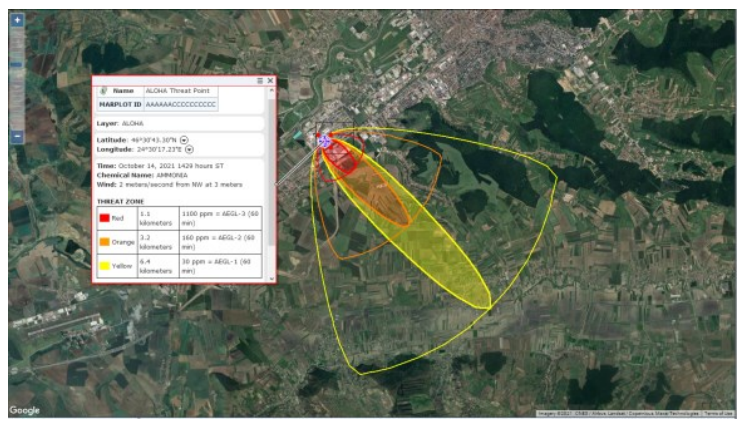

Fig. 4. Toxic release threat zone plotted using MARPLOT - ammonia

In case of the simulation for the first accident scenario carried out with Phast, the maximum toxic gas cloud footprint reaches the ERPG indices the following distances downwind from the source of release:

- ERPG $125 \mathrm{ppm}$ up to a maximum distance of $3.1 \mathrm{~km}$;

- ERPG $2150 \mathrm{ppm}$ to a maximum distance of $1.5 \mathrm{~km}$;

- ERPG $3750 \mathrm{ppm}$ to a maximum distance of $750 \mathrm{~m}$.

These results of the simulation have been plotted on the map (Figure 5) and the toxic cloud maximum footprint is presented graphically in Figure 6.

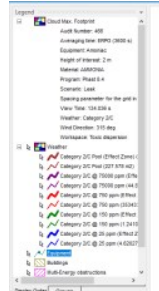

Fig. 5. Phast results plotting - ammonia

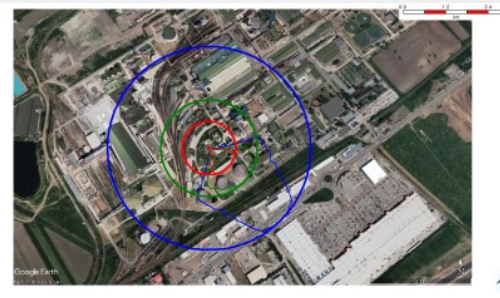

Fig. 6. Cloud maximum footprint - ammonia

Simulation performed with ALOHA reveals the fact that for the discharge of hydrogen chloride from the tank through the circular $5 \mathrm{~cm}$ hole, the toxic gas cloud reaches the AEGL indices at the following distance from the source of release:

- AEGL $11.8 \mathrm{ppm}$ at a maximum distance of approximately $10 \mathrm{~km}$;

- AEGL $222 \mathrm{ppm}$ at a distance of de $4.1 \mathrm{~km}$; 
- AEGL $3100 \mathrm{ppm}$ at a distance of de $2.2 \mathrm{~km}$.

The toxic threat zone is represented graphically in Figure 7 and plotted using MARPLOT, as shown in Figure 8.

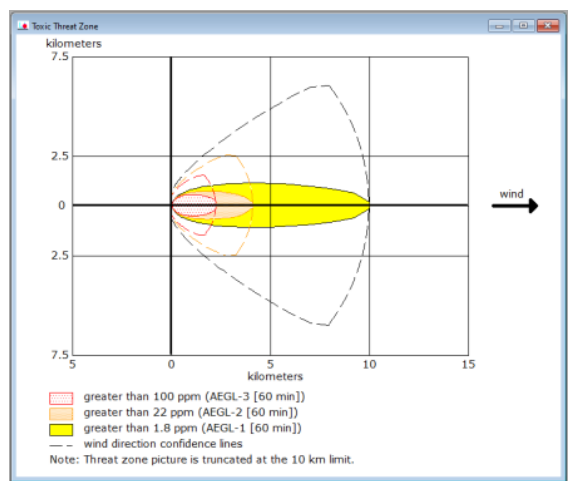

Fig. 7. Toxic threat zone - hydrogen chloride release

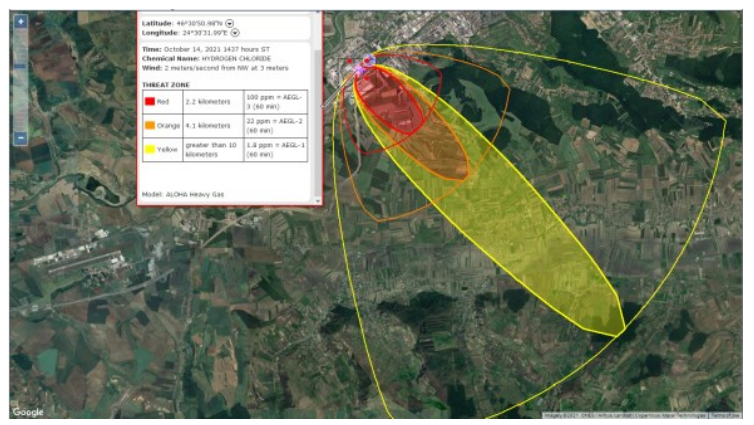

Fig. 8. Toxic release threat zone plotted using MARPLOT - hydrogen chloride

In case of the simulation for the second accident scenario carried out with Phast for hydrogen chloride release, the maximum toxic gas cloud footprint reaches the ERPG indices the following distances downwind from the source of release:

- ERPG $13 \mathrm{ppm}$ up to a maximum distance of $6.5 \mathrm{~km}$

- ERPG $220 \mathrm{ppm}$ up to a maximum distance of $3 \mathrm{~km}$

- ERPG $3150 \mathrm{ppm}$ up to a maximum distance of $1.5 \mathrm{~km}$

These results of the simulation have been plotted on the map (Figure 9) and the toxic cloud maximum footprint is presented graphically in Figure 10.

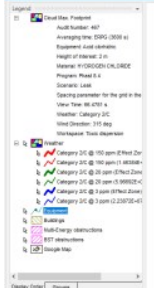

Fig. 9. Phast results plotting - hydrogen chloride

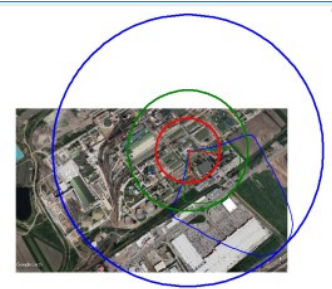

Fig. 10. Cloud maximum footprint - $\mathrm{HCl}$

\section{Conclusions}

Ensuring safety against chemical accidents that may occur in industrial units carrying toxic substances is imperative to avoid adverse consequences for people and the environment.

ALOHA and Phast QRA software can simulate and foresee the consequences of possible chemical accidents. There have been obtained various results from the modelling carried out with both software.

The results obtained from the two modelling programs provide important data for analysing the plant layout and for predicting the effect of toxic dispersion on the nearby population.

Due to the discrepancies in output values of different software, certain issues arise during the model comparison. 
The geometrical effects of the programs contribute to differences between simulation tools. Buildings, terrain and geometry, in general, will have recirculation zones that will influence the local air movements.

Differences in simulation tools are due to the geometrical impacts of the programs. Recirculation zones will be created by buildings, terrain, and geometry in general, which will impact local air movements.

Accident investigations can benefit from hazardous dispersion modelling tools. Another possible application for this software is the identification of hazardous and non-hazardous zones in chemical facilities. Workers could be informed about the identified dangerous areas and how to react in the event of a chemical accident in an emergency situation.

Several scenarios could be modelled without the need for hazardous experiments.

This paper was developed within the Nucleu-Programme, carried out with the support of Romanian Ministry of Education and Research, project no. PN-19-21-02-01, project title: Techniques and solutions for developing the scientific and technical competences for prevention and protection to explosions (in Romanian: Tehnici si solutii pentru dezvoltarea competentelor stiintifice si tehnice de prevenire si protectie la explozie).

\section{References}

1. M. Polorecka, J. Kubas, P. Danihelka, K. Petrlova, K. Repkova Stofkova, K. Buganova, Sustainability, 13, (2021)

2. H. Esfandian, M. Goodarzian Urimi, A. Shokoohi Rad, International Journal of Engineering, 34, 4, (2021)

3. H.E. Lee, J.R., Sohn, S.H. Byeon, K.W. Moon, IJERPH, 15, 8, (2018)

4. A. Naemnezhad, A.A. Isari, E. Khayer, E. et. al, Model. Earth Syst. Environ,. 3, 43, (2017)

5. X. Wang, X. Ma, IOP Conf. Ser.: Earth Environ. Sci., 680, 012119, (2021)

6. S. Shojaee Barjoee, M. Nikbakht, E. Malverdi, S. Zarei Mahmoud Abadi, M.R. Naghdi, Pollution, 7, 1, (2020)

7. J.Y. Choi, S.H. Byeon, IJERPH, 17, 2849, (2020)

8. Phast Software features. Available on https://www.dnvgl.com/services/process-hazard-analysissoftware-phast-1675

9. V.M. Pasculescu, E. Ghicioi, M.S. Morar, D. Pasculescu, M.C. Suvar, Quality - Access to Success, 20, 25-30, (2019)

10. V.A. Florea, D. Pasculescu, V.M. Pasculescu, Mining of Mineral Deposits, 15, 3, (2021)

11. V.M. Pasculescu, M.S. Morar, C.R. Cioara, L I. Tuhut, A.D. Babut, EDS Web of Conferences, 241, 03003, (2021) 